\title{
Erratum to: Hydrogeochemical investigations in a drained lake area: the case of Xynias basin (Central Greece)
}

\author{
Nikos Charizopoulos • Eleni Zagana • \\ Georgios Stamatis
}

Published online: 16 September 2016

(C) Springer International Publishing Switzerland 2016

Erratum to: Environ Monit Assess (August 2016)

188, Issue 8:480

DOI 10.1007/s10661-016-5484-z

The original version of this article unfortunately contained a mistake.

The Figure 2 was published erroneously.

The corrected Figure 2 is shown in the next page.

The online version of the original article can be at under doi:10.1007/s10661-016-5484-z.

N. Charizopoulos $(\bowtie) \cdot$ G. Stamatis

Laboratory of Minearology-Geology, Agricultural University of Athens, Iera Odos 75, 11855 Athens, Greece

e-mail: nchariz@gmail.com

G. Stamatis

e-mail: stamatis@aua.gr

E. Zagana

Department of Geology, Laboratory of Hydrogeology, University of Patras, 26110, Rio-, Patras, Greece

e-mail: zagana@upatras.gr 


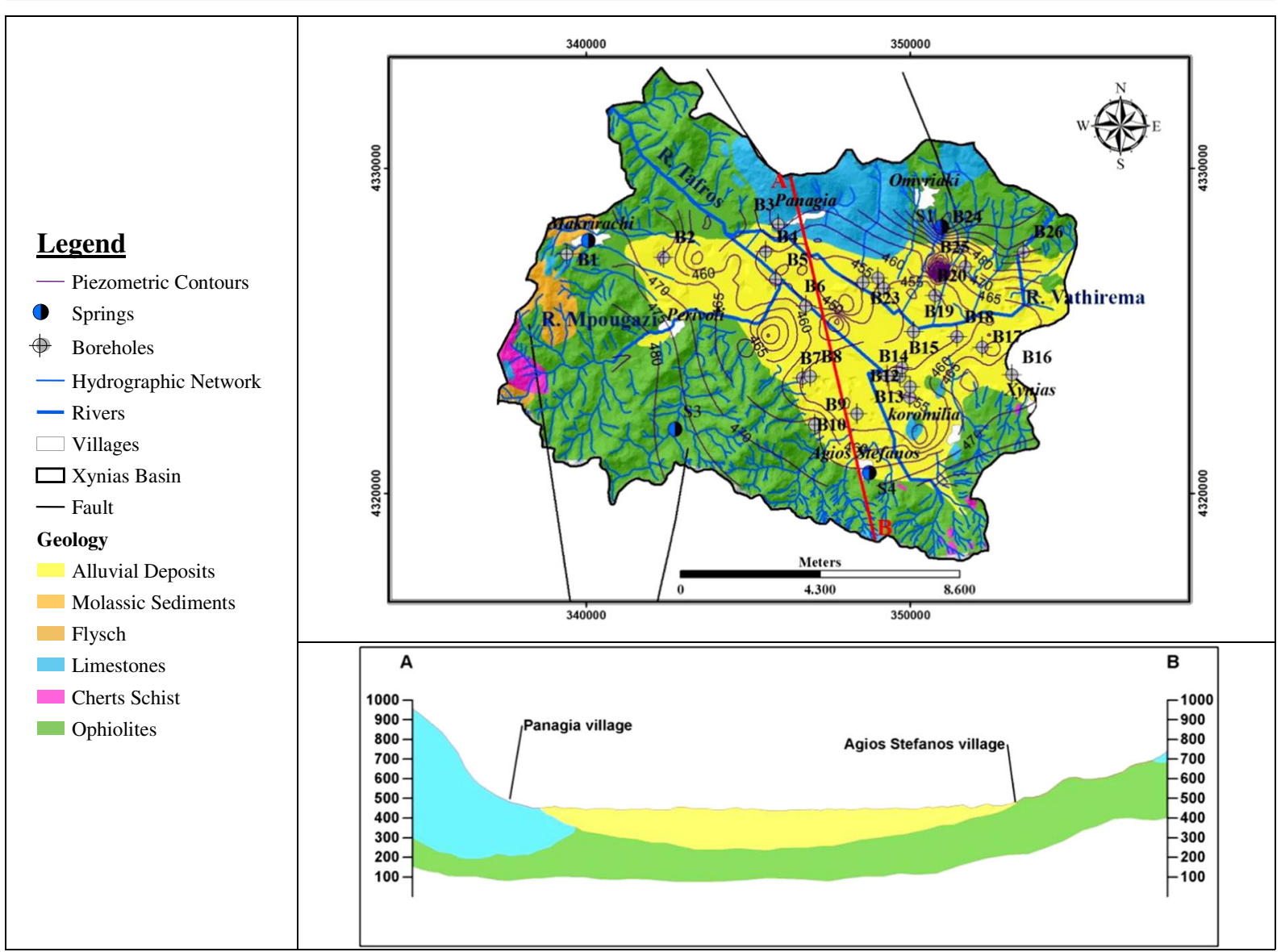

Fig. 2 Geology setting map and schematic geological cross section of the Xynias basin 